\title{
DIFERENÇA NO CURRÍCULO
}

\author{
MARLUCY ALVES PARAÍSO \\ Professora da Faculdade de Educação e coordenadora do Grupo de Estudos \\ e Pesquisas em Currículos e Culturas da Universidade Federal de Minas Gerais, \\ pesquisadora do Conselho Nacional de Desenvolvimento Científico e Tecnológico \\ marlucy.paraiso@terra.com.br
}

\begin{abstract}
RESUMO
O artigo procura pensar um currículo com a diferença, conforme conceituada por Gilles Deleuze, para abalar os extratos dos currículos já formados e experimentar fazer um currículo movimentar-se. Traz, como mote para essa experimentação, linhas de currículos traçadas em uma investigação que cartografou os fazeres curriculares de três professoras que trabalham em três escolas distintas. Utiliza vários conceitos retirados do pensamento da diferença deleuziano para pensar linhas virtuais no território do currículo. Defende a necessidade de pensar o currículo em suas bifurcações, em seus escapes, variações e linhas de fugas. Prioriza a diferença em vez da identidade, e segue as ramificações que surgem desse pensamento. Procura fazer traçados que racham os extratos dos currículos existentes, em seu meio, para ver a diferença fazer 0 seu trabalho. Experimenta, por fim, fazer a diferença operar para pensar um currículo como território de multiplicidades, somas, desejo, desterritorializações, cultivo de alegrias e afectos. CURRÍCULO - DIFERENÇA - GILLES DELEUZE
\end{abstract}

\begin{abstract}
DIFFERENCE IN THE CURRICULUM. This paper intends to consider a curriculum with the difference, as conceptualized by Gilles Deleuze, in order to shake the extracts of the already existing curriculums so as to give rise to a new one. It brings, as a means of experimentation, lines traced in an investigation which has mapped out the curriculum of three teachers working in three different schools. Concepts taken from the deleuzian thought on difference are used to establish virtual lines in the territory of the curriculum. The need to consider the curriculum with its bifurcations, escapes, variations and escape lines is defended. Difference is prioritized, as opposed to identity, and the ramifications that emerge from this thought are then followed up on. Its lines and traces aim to break the extracts of the already existing curriculums so as to enable us to observe difference doing its job. Last but not least, it means to operate with difference in such a way that the curriculum may be viewed as a multiple territory of summation, desire, extinction of territorial boundaries as well as cultivation of joys and affections.

CURRICULUM - DIFFERENCE - GILLES DELEUZE
\end{abstract}


Um currículo é diferença por natureza; é pura diferença; é diferença em si. Afinal, é um território de multiplicidades de todos os tipos, de disseminação de saberes diversos, de encontros "variados", de composições "caóticas", de disseminações "perigosas", de contágios "incontroláveis", de acontecimentos "insuspeitados”. Um currículo é, por natureza, rizomático, porque é território de proliferação de sentidos e multiplicação de significados. Apesar de todos os poderes que fazem o controle, demarcam as áreas e opinam sobre como evitar a desorganização em um currículo e que demandam sua formatação, tudo vaza e escapa.

É certo que um currículo é também território povoado por buscas de ordenamentos (de pessoas e espaços), de organizações (de disciplinas e campos), de sequenciações (de conteúdos e níveis de aprendizagens), de estruturações (de tempos e pré-requisitos), de enquadramentos (de pessoas e horários), de divisões (de tempo, espaço, áreas, conteúdos, disciplinas, aprendizagens, tipos, espécies...). Isso tudo porque o que está em jogo em um currículo é a constituição de modos de vida, a tal ponto que a vida de muitas pessoas depende do currículo.

Mas, se mesmo com os investimentos para controlar a diferença no currículo, tudo aí ainda vaza, por que não pensar o currículo por meio de suas bifurcações? Por que não experimentar no currículo o jogo da diferença? Por que não pensar o currículo por meio dos seus vazamentos, escapes, suas linhas de fugas, distorções e variações? Por que não priorizar a diferença em vez da identidade e seguir as ramificações que surgirem desse pensamento?

Gilles Deleuze - como um filósofo da multiplicidade que pensou a repetição (que é, também, diferença) e o acontecimento - exalta e reivindica a diferença em si: o diferenciar-se em si da própria coisa. No plano da diferença, constrói sua filosofia e inventa conceitos.

Toda a discussão que faz sobre diferença desloca completamente os sentidos a ela comumente atribuídos, já que em vez de buscar o comum sob a diferença, pensa "diferencialmente a diferença". Em vez da identidade, que tenta reduzir a diversidade a um elemento comum, Deleuze prefere a diferença em si, a variação, a multiplicação, a disseminação e a proliferação. A diferença é pensada não como uma característica relativamente geral a serviço da generalidade do conceito, mas sim como puro acontecimento. Em vez do uno, do todo, da origem, valoriza a multiplicidade, a diferenciação, a repetição e a improvisação. Isso porque a diferença em Deleuze não é da ordem da repre- 
sentação; não é um produto e nem resultado. A diferença também não se refere ao diferente; não é relação; não é predicativa e nem propositiva. A diferença nunca é diferença entre dois indivíduos. Contra a diferença entre coisas ou entes determinados, Deleuze afirma a diferença em si: "a diferença interna à própria coisa", o "diferenciar-se em si da coisa". É claro que esse pensamento pode deixar-nos perplexos. Afinal, sempre pensamos a diferença, no território do currículo, em sua relação com a identidade. Sempre pensamos a diferença entre entes e coisas. Estamos acostumados a nos preocupar com o diferente. Entretanto, o diferente é irrelevante para a diferença deleuziana. $\bigcirc$ relevante para a diferença é a singularidade, o fluir de forças, a transgressão. A diferença em Deleuze é interior à Ideia, entendida como "multiplicidade substantiva" ou como "sistema de diferenças". Um sistema de diferenças é determinado por uma complexa articulação de diferençações e diferenciações. As diferençações acontecem em uma das metades da Idéia, no seu lado "distinto-obscuro": distinto devido a suas relações diferenciais e suas singularidades, e obscuro porque esses elementos não estão ainda atualizados. Essa metade, em que operam diferençações, é também chamada virtual. $\bigcirc$ virtual, em Deleuze, possui plena realidade, uma vez que para ele, a realidade do virtual é como a de uma "tarefa a ser cumprida", ou de "um problema a ser resolvido". Já as diferenciações acontecem como linhas de um processo de atualização. Atualização que se faz por processo de "diferença, divergência ou diferenciação", rompendo com a semelhança como processo e com a identidade como princípio.

Entendendo o virtual, portanto, como real "potencial" e não como "conjunto de possibilidades", as linhas de diferenciação não são linhas de realização de certas possibilidades, mas sim "movimentos de criação" fundados pela diferença e repetição. Deleuze defende que "uma vida não contém nada mais do que virtuais. Ela é feita de virtualidades, acontecimentos, singularidades". O virtual "não é algo ao qual falte realidade, mas que se envolve em um processo de atualização ao seguir o plano que lhe dá sua realidade própria". Nesse sentido, "não há nada, absolutamente nada, que [...] esteja definitivamente formado, nem mesmo aquilo que na ontologia deleuziana, poderia dar essa impressão, isto é, as entidades do domínio do atual".

Estendendo as linhas virtuais no currículo, podemos dizer que um currículo também não está nunca definitivamente formado. Precisamos, então, rachar os extratos, rachar os currículos existentes em seu meio para ver a diferença fazer o seu trabalho. Nessa perspectiva, podemos, sim, experimen- 
tar fazer a diferença operar para movimentar um currículo, para pensar um currículo. É isso que faço neste artigo.

Com base no pensamento deleuziano, procuro as possibilidades de um currículo, e pergunto aos currículos investigados: "o que pode"? Procuro pensar um currículo com a diferença para abalar os extratos dos currículos já formados e fazer um currículo movimentar-se. Trago, como mote para essa experimentação, linhas de currículos traçadas em uma investigação que cartografou as experimentações e os fazeres curriculares de três professoras que trabalham com a alfabetização de crianças em três escolas distintas de Belo Horizonte: uma pública estadual, uma pública municipal e outra particular. Cartografar um currículo é construir um mapa aberto dos seus segmentos (poderes e territórios) e dos seus pontos de desterritorialização (por onde um currículo foge e faz fugir). Para se fazer uma cartografia, conforme sugerem Deleuze e Guattari (1997), é necessário analisar "a longitude e a latitude" (p.42). A longitude "está relacionada às partes do corpo": de que esse corpo se compõe? Já a latitude refere-se ao "grau de potência de um corpo" (p.42): quais são os afectos desse corpo?

A investigação que subsidia este artigo teve como objetivo cartografar as experimentações e os fazeres curriculares de três professoras que trabalham com a alfabetização em três escolas que adotam propostas de organização de ensino e de currículo muito distintas. Essas escolas são, também, de redes diferentes: uma da rede municipal de Belo Horizonte, outra da rede particular e outra da rede estadual de Minas Gerais. As professoras utilizam materiais pedagógicos distintos e possuem objetivos que tornam seus fazeres curriculares muito diferentes entre si. As práticas das professoras foram acompanhadas e registradas durante um ano letivo inteiro. Além disso, as três professoras participaram, durante um ano e meio, de encontros mensais com a equipe pesquisadora'. Esses encontros tinham como objetivo discutir aquilo que havia

I. Registro aqui meu agradecimento a essas três professoras (não as identifico porque esse foi o nosso acordo) que se envolveram completamente e de forma intensa com a investigação. Mesmo cansadas pelo trabalho exaustivo de docentes, um sábado por mês, durante um ano inteiro, elas vinham até a Universidade Federal de Minas Gerais - UFMG - para participar das reuniões com a equipe pesquisadora. Duas dessas professoras trabalhavam em dois turnos, e a outra trabalhava em um turno e fazia o curso de pedagogia no outro. Desse modo fazer parte da pesquisa significava usar seu pouco tempo livre para colaborar com a investigação. Nessas reuniões, realizadas das 8 às 12 horas, elas participavam intensamente das discussões 
sido registrado de suas práticas nas observações, para que pudéssemos refazer e remontar os mapas que estavam sendo traçados pela equipe da pesquisa

Ao fazer a cartografia, recompus um mapa dos currículos pesquisados e pude registrar um conjunto de "linhas dispersas", funcionando todas ao mesmo tempo, "em velocidades variadas" (Deleuze, 1992, p.47). A cartografia ou o mapa, segundo Deleuze e Guattari (1995, p.22), é aberto, conectável, desmontável, composto de diferentes linhas, "suscetível de receber modificações constantemente". As linhas "são elementos constitutivos das coisas e dos acontecimentos" e, por isso mesmo, são constitutivas dos currículos das diferentes escolas investigadas.

Utilizo conceitos retirados do pensamento da diferença deleuziano para pensar essas experimentações curriculares de professoras no currículo menor; isto é, aquele feito no cotidiano das escolas. Silvio Galo (2002), inspirado em Deleuze e Guattari ( 1977 ) que pensa uma "literatura menor", pergunta: "por que não pensamos numa educação menor?" Para Galo a educação menor é feita na sala de aula, no cotidiano de professores e alunos. Gauthier (2002) também fala da importância do "uso menor da pedagogia", que "não pode outra coisa que não questionar, às vezes até mesmo à sua revelia" (p. I 52), "a pedagogia maior".

Este artigo, nessa mesma linha, junta-se a esses trabalhos para pensar o currículo menor, que é aquele feito no cotidiano das escolas.

\section{PRIMEIRO: UM ADEUS À IDENTIDADE}

O pensamento curricular é, na contemporaneidade, um pensamento identitário. Buscamos responder no currículo: "o que é mesmo?" Queremos saber o que é um currículo por competências? Falamos das semelhanças entre o currículo por competências e o currículo por objetivos. Procuramos identificar currículos pós-críticos e distingui-los dos críticos. Apontamos semelhanças e diferenças entre o currículo oficial e o alternativo. Queremos saber o que é um currículo multicultural. Queremos saber o que é mesmo um currículo organizado por projetos de trabalhos. $\bigcirc$ que é um currículo tradicional ou

do que registrávamos nas observações de suas aulas, além de colaborarem com a escrita das atas para sintetizar e sistematizar as discussões coletivas com a equipe pesquisadora. Isso foi feito sempre com disposição, ânimo e alegria admiráveis. 
construtivista? O que é um currículo escolar e um currículo de outros artefatos? Olhamos para a variedade de pensamentos existentes, de coisas, de indivíduos, de práticas sociais procurando classificar, encontrar a unidade, aquilo que as identifica: a identidade. Buscamos o comum sob a diferença.

Além disso, no campo curricular, a identidade goza de absoluto prestígio. Considerando o currículo como "um espaço de produções de identidade", o tema ganha destaque nas produções sobre currículo no Brasil e nas discussões de currículo da Associação Nacional de Pós-Graduação e Pesquisa em Educação - Anped -, em especial a partir do início dos anos 90. É certo que, com contribuições de campos como os Estudos Culturais, os Estudos Feministas e o Pós-colonialismo, a identidade ganha outras qualidades: "multifacetada", "fragmentada", "diversificada”, "híbrida”, "pós-moderna”. Isso para responder aos problemas já identificados pelas próprias teorias culturais e sociais; segundo elas, os sujeitos são multifacetados e existe uma "dispersão da identidade" na contemporaneidade. Contudo, ainda assim, mesmo quando é pensada na sua relação com a diferença, é a identidade que está em foco.

Pensar o currículo com a diferença deleuziana é tirar o foco da identidade: tanto do pensamento identitário (que tem como critério a reunião) como do conceito de identidade (que procura o comum sobre a diversidade ou que identifica pessoas e grupos para, em seguida, agrupá-los como diferentes). Se a reunião é o critério da generalidade e da identidade, o acontecimento é o critério da diferença. Então a diferença é comportar-se em relação a algo que não tem semelhante ou equivalente. A diferença é o que vem primeiro; é o motor da criação; é a possibilidade de no meio, no espaço-entre, começar a brotar hastes de rizoma. Diz respeito àquilo que está ainda em vias de se formar: de currículos que são "realidade em potencial", que ainda não foram formados.

Os currículos deste mundo, os já existentes, são mesmo, sempre, currículos já formados. Olhamos para esses currículos e vemos estratos já constituídos: disciplinas, saberes, professoras, crianças, identidades, livros didáticos, conteúdos, literatura infantil e juvenil, exercícios, atividades, conhecimentos, mesas, carteiras enfileiradas ou em círculos, conversas, explicações, projetos, atividades, ensino... Até pode haver metarmofoses, transformações, mudanças, mas são sempre processos secundários aos estratos formados que daí resultam. Com os pensamentos curriculares que aprendemos a usar, olhamos para os 
currículos existentes buscando essas coisas, pensando naquilo que já foi formado, em organizar o caos ou a desorganização que venha a se manifestar.

Os currículos com os quais lidamos no nosso ofício de curriculistas pedem algum princípio, algum método, alguma categoria que organize essa diversidade existente em "tipos" mais gerais e abrangentes, classificando, agrupando e identificando as coisas e as pessoas. Olhamos para a variedade de coisas existentes, comparamos as coisas entre si e delas extraímos diferenças e semelhanças. E ainda mais: costumamos "esquecer", anular as diferenças para identificar as coisas, sintetizar, dizer o que é "essencial" de um currículo. Classificamos, fazemos tipologias. Trata-se de pensamentos concentrados na identidade: o que no diverso permanece igual?

Acostumados a olhar por meio da identidade, a operar com a identidade, como fazer a diferença deleuziana proliferar em um currículo? Como pensar com a diferença e não com o diferente que é a nossa referência, quando trabalhamos com o multiculturalismo, com a diversidade cultural, com os Estudos Culturais, com as narrativas étnicas, com as ações afirmativas? Que virtualidades, que singularidades seriam imanentes a um currículo? Deleuze "lança uma flecha", dá uma pista, quando diz:

Certamente, o E é a diversidade, a multiplicidade, a destruição das identidades. [...] a multiplicidade nunca está nos termos, seja qual for o seu número, nem no seu conjunto ou na totalidade. A multiplicidade está no E, que não tem a mesma natureza dos elementos nem dos conjuntos. (1992, p.60)

Recolho então essa flecha para estender a linha do "e", e para deixar a diferença fazer o seu trabalho no currículo.

\section{SEGUNDO: RECOLHENDO A FLECHA DO “E”}

Nas observações de três currículos investigados, foi possível traçar linhas estendidas naqueles territórios que trazem ecos e ressonâncias de pensamentos curriculares já bem conhecidos:

- No currículo I, a imagem de pensamento que ecoa é a do currículoplural: conhecimento-é-construído, criança-aprendiz, avaliaçãoprocessual-e-contínua, trabalho-coletivo, enturmação-por-idade, 
trabalho-com-projetos. Além disso, vemos no território de um fazer curricular, que é animado pelo pensamento currículo-plural, mistos de outros pensamentos curriculares: professora-ensina, tarefas-escolares, sair-do-estágio-do-não-saber-para-o-saber, conteúdo-sem-sistematização-nos-anos-iniciais.

- No currículo 2, a imagem de pensamento ressonante é a do currículoconteudista: agrupamento-por-nível-de-aprendizagem; seriação; remanejamento-de-crianças; ênfase-no-conteúdo; conteúdossequenciados, currículo-disciplinar, participação-e-ajuda-mútua, ensino-com-livro-didático, professora-que-ensina, planejamentocom-base-nos-Parâmetros-Curriculares-Nacionais (PCN).

- No currículo 3, há ecos da imagem de pensamento do currículo-construtivista: conhecimento-construído-pela-criança, criança-participantedas-decisões-sobre-o-que-quer-aprender, partir-do-concreto-para-oabstrato, currículo-aberto, eixos-curriculares-feitos-pela-escola, interesse-do-aluno, escrita-construção, aprendizagem-na-diversidade.

Essas três imagens de currículo, pensadas com a diferença, fazem parte de um mesmo núcleo de pensamento: dos currículos já formados, dos currículos já pensados, das coisas atualizadas. Entretanto, como afirma Deleuze, "não há obra que não indique uma saída para a vida, que não trace um caminho entre as pedras", porque tudo escapa. Um escape, um vazamento, uma saída pode vir de qualquer lugar. Um novo rizoma pode brotar "no coração de uma árvore, no oco de uma raiz ou na axila de um galho". Precisamos então ficar permanentemente à espreita em um currículo. "O grande desafio, para o cartógrafo, é manter-se atento a tudo o que acontece" em um currículo ao mesmo tempo. O grande desafio é registrar as linhas de um currículo fazendo o "E" das multiplicidades funcionar.

Para ver e sentir a diferença proliferar, então, é preciso pensar em multiplicidades: afinal, se um código de currículo funciona é porque, uma professora que é uma das codificadoras de um currículo, faz parte de uma multidão, de uma matilha curriculante. Para operar por multiplicidade, um currículo é despojado de qualquer significação, já que não se forma a não ser no processo de anulação dos referentes. Isso porque a energia provém do processo de desmontagem de todos os modelos de currículos já incorporados. 
Nesse sentido, dos eixos-curriculares-feitos-pela-escola, dos ParâmetrosCurriculares-Nacionais, das tarefas-escolares, dos livros-didáticos, dos remanejamentos-de-crianças e dos exercícios-escolares, que procedem por decalques, podem começar a brotar um novo rizoma (como em uma obra de arte ou em um livro de Deleuze). Isso porque o que precipita a criação de uma matilha em um currículo pode vir de lugares insuspeitados, e pode ser qualquer coisa. Assim, para ver, sentir e registrar o jogo da diferença, em vez do "é" (que remete à identidade), devemos priorizar o "e" (que remete à multiplicidade). $\bigcirc$ "e" é o entre-espaço de um currículo, é o que está no meio, que cresce no meio dos currículos; aquelas hastes de rizomas que brotam, crescem e se bifurcam.

Ao olhar no meio dos currículos-estratos vemos muito mais do que decalques. Vemos linhas que não formam qualquer contorno, mas que potencializam aqueles que vivenciam um currículo. Linhas que criam perceptos (novas maneiras de ver e ouvir) e afectos (novas maneiras de sentir) que aumentam a potência de agir. Linhas que operam por multiplicidades. Vemos então um currículo-multiplicidade anular os referentes anteriores e utilizar-se de múltiplas linguagens, tais como: música (orquestras, cantigas, músicas clássicas, música popular brasileira), pintura, literatura, ciência, poesia, gestos, corpos, falas, curtos silêncios, silêncios longos, gritos, lágrimas, sorrisos, emoções, imagens, figuras, filmes, desenhos... Vemos ainda um currículo colocar essas linguagens em relação com o que está sendo ensinado, e o que está sendo ensinado transforma-se em virtual, ou seja, em "tarefa a ser cumprida". Por meio desse virtual, engrenam-se vários movimentos curriculares que, embora heterogêneos, se afectam uns nos outros.

Operar por multiplicidade, então, é operar com a diferença em si; é operar com o devir. E "um devir não é um nem dois, nem relação de dois, mas entre dois, fronteira ou linha de fuga, de queda, perpendicular a dois". Experimento então trazer exemplos de devires, traçando aquilo que cresce no meio dos currículos formados.

\section{TERCEIRO: PARTIR OS CURRÍCULOS E TRANSFORMÁ-LOS EM OUTRA COISA}

Registrar um currículo-diferença é acompanhar linhas e traçados de currículos em suas bifurcações; ver, sentir e falar de sua força, sua potência, sua composição, seus movimentos de criação. E "criar, não é comunicar mas 
resistir". Resistir aos estratos, ao já feito, ao já construído, ao "é". Resistir a tudo aquilo que nos entristece, que diminui nossa potência, nossos desejos e nossa força de pensar e traçar linhas de fugas. Observar e acompanhar os traçados do acontecimento, a potência criadora, o precipitar de um devir-minoritário, os "bons encontros" (aqueles que aumentam nossa potência de agir). Lembrar nesses traçados que "se a troca e a reunião são os critérios da generalidade e da identidade", o "roubo e o acontecimento são os critérios da diferença".

Um currículo, visto pelo meio, com inspiração no pensamento da diferença deleuziano, não se fecha nunca; está permanentemente aberto a novos acréscimos. Um currículo assim é difícil de ser descrito e apreendido. Entretanto, para propósitos de ofícios de pesquisadora-curriculista, traço linhas sumárias das possibilidades de um currículo, por meio de seis exemplos de linhas cartografadas de experimentações curriculares que se bifurcam, metarmofoseiam e escapam ao currículo maior. Contudo, atenção: "as linhas e os traços vêm forçosamente de mim, mas eles só são bem-sucedidos" se são os currículos praticados "quem vem ocupar o desenho".

\section{Exemplo I: O gosto de somar}

Em um currículo cartografado vê-se um procedimento ordinário do currículo-que-faz-remanejamento-de-crianças (para agrupá-las e reagrupá-las por nível de aprendizagem) tornar-se um acontecimento. Esse procedimento ordinário do currículo-conteudista inspira perceptos e afectos em um bando de crianças e em uma professora. Esta, em seu devir-criança, é afetada pelas sensações produzidas pela retirada de uma criança daquele território curricular. Os gritos: "Ítalo! Ítalo! Ítalo! Ítalo!" (som das "minorias que não param de resistir") não trazem Ítalo de volta para aquela sala-de-aula, mas fazem com que o grupo aprenda a fazer matilha, a fazer composições, a disseminar, naquele território, "novas maneiras de pensar". Vi, senti e ouvi os extratos do currículoremanejador estremecerem sem que precisasse de qualquer curriculista crítico, pós-crítico, construtivista ou plural para denunciá-lo. Aquele bando, naquele momento, aprende o gosto e a alegria de somar, multiplicar; nunca subtrair e nem dividir. Aprende a mostrar suas tristezas pela perda de um colega e a reivindicar a alegria de ter alguém de quem se gosta por perto. Aprende a ligar multiplicidades, fazer conexões e composições e desterritorializar as regras e as leis do currículo-enturmação-por-nível-de-aprendizagem. 


\section{Exemplo 2: Desterritorializações}

O aprender a ler é um acontecimento em um currículo. Mas não é um aprender a ler qualquer. É o aprender a ler de duas crianças (em uma sala com trinta e duas) que não se conectavam com os signos da leitura. Agiam na incerteza e na obscuridade até que aceitam que não vão mais ler naquele ano. Mas a professora convoca a turma (não com a fala ou projetos, mas com gestos e ações) a fazer contágio de alegrias e de devires-minoritários. O contágio e a ocupação daquele território é de tal proporção que em alguns momentos não se tem mais na turma 32 crianças e uma professora. $\bigcirc$ número quase se reverte, e passamos a ver 30 crianças em seu devir-mestre e uma professora em seu devir-criança na empreitada para que Rubem e Chiara aprendam a ler. "Eis porque é tão difícil dizer como alguém aprende: há uma familiaridade prática, inata ou adquirida, com os signos, que faz de toda a educação, alguma coisa amorosa, mas também mortal”. Então, após partilhar o comprometimento, quando Chiara e Rubem leem em sala de aula, o território curricular vira espaço de festa; espaço para compartilhar o gozo e a alegria vivenciados pelas crianças que aprenderam. É claro que para isso foi necessário que deixassem "passar alguma coisa, uma corrente de energia" por todos que desterritorializaram o currículo-reprovador-repetente.

\section{Exemplo 3: Desejo}

Traços intensivos começam a trabalhar por conta própria no espaço-entre as linhas segmentares que constituem um currículo. Em movimentos ora lentos e ora absolutamente velozes, um currículo desterritorializa-se porque consegue emitir signos e afecções que envolvem afectos potencializadores. Imaginem que em um currículo pesquisado, do Sistema Mineiro de Avaliação da Educação - Simave - que opera por decalque porque classifica, hierarquiza, gosta de partilha, do controle e da organização - começa a brotar um traço intensivo por sua conta. Esse traço incita a positividade do desejo em um currículo. Desejo que, em Deleuze (1 994), não é falta, mas "imanência" e "potência". Tendo sido classificada em segundo lugar no Estado de Minas Gerais e em primeiro, no município de Belo Horizonte por essa avaliação, a escola sente um orguIho que contagia crianças e professoras, e abre uma brecha para arriscarem a fazer outras coisas além do já feito e do planejado. Isso se soma a um prêmio 
que a professora observada ganhou por um projeto realizado com as crianças sobre "literatura e produção de textos". Não interessa se não consegue mais o mesmo resultado no ano seguinte. Interessa que desse procedimento corriqueiro do currículo-avaliador-hierárquico consegue-se seguir linhas que fazem fugir. Professora e crianças tiram do episódio aquilo que potencializa a todos: o desejo de aprender; a vontade de escrever poesias, contos, histórias, textos; a necessidade de pensar, inventar, criar.

Talvez pudéssemos imaginar que seria uma contradição que uma avaliação oficial que diz "a escola é ótima" (a melhor do município e a segunda do estado) provoque a vontade de mudar e não de continuar. Contudo, como diz Deleuze, "um campo social não se contradiz, mas ele foge, e isto é primeiro. Ele foge de antemão por todos os lados; as linhas de fuga são sempre primeiras (mesmo que primeiro não seja cronológico)". Diz ainda que "longe de estar fora do campo social ou dele sair, as linhas de fuga constituem seu rizoma ou cartografia. [...] Elas são as pontas de desterritorialização nos agenciamentos de desejo".

\section{Exemplo 4: Aprender}

Em um currículo vemos uma reunião de pais com a professora, procedimento também comum no currículo-disciplinar, transformar-se em saída para destruir aquilo que ironiza, mortifica, apaga e aprisiona. "Basta que o ódio seja suficientemente vivo para que dele se possa tirar alguma coisa, uma grande alegria, não de ambivalência, não a alegria de odiar, mas a alegria de querer destruir aquilo que mutila a vida". As reuniões, feitas no horário em que as crianças estão fazendo educação física, têm tempo predefinido. Um dia, no entanto, a reunião acabou e os pais não saíram da sala. As crianças chegaram da educação física e encontraram os pais. A alegria foi quase geral. As crianças abraçaram os pais e sentaram no seu colo. Então o Samuel vai sentar no colo da mãe, e esta o impede com um olhar. Sem emitir uma única palavra, a mãe Ihe mostra, com gestos, o seu lugar: deve sentar-se no chão. Ele senta-se no chão e abraça as pernas. A professora fica mortificada naquele instante. Mas

.... diferenciação dá-se quando uma inesperada ruptura acontece, quando algo incita a um começo, já que ela é heterogênea, da ordem do quase-vazio, da 
quase-causa, paixão que é marca da linha de fuga, expressão da virtualidade: devir acontecimento. (Corazza, 2004, p.54)

Talvez esse procedimento fosse bastante conhecido por Samuel, mas tocou a professora a tal ponto que a partir dali, do ódio e da tristeza que sente, encontra energias para destruir aquilo que entristece Samuel, que dificulta seu encontro com outros signos, que atrapalha sua aprendizagem. Como "ninguém sabe antecipadamente os afectos de que é capaz; é uma longa história de experimentação", a professora passa a fazer composições com o Samuel, a propiciar encontros dele com uma infinidade de signos e linguagens na luta para que algo o toque amorosamente e o ajude a fugir das atas do poder que o entristece e enfraquece. A professora parece saber muito bem que "nada aprendemos com aquele que nos diz: faça como eu. Nossos únicos mestres são aqueles que nos dizem 'faça comigo' e que, em vez de nos propor gestos a serem reproduzidos, sabem emitir signos a serem desenvolvidos no heterogêneo".

\section{Exemplo 5: A cultura da alegria}

No meio de um currículo investigado, embora tudo esteja planejado, organizado e a "rotina diária" do currículo seja inclusive enumerada e escrita no quadro para que todos possam acompanhar as "tarefas" de cada dia, vemos a simples "leitura de uma história de um maestro" fazer tudo se desorganizar por vários dias no território de um currículo. Vemos um currículo seguir outro rumo e escapar ao já pensado. Para isso, no entanto, os habitantes do território curricular precisam aceitar deixar o mapa, e arriscar uma viagem sem percurso definido, sem ponto de chegada. Vemos, então, em um currículo que, de fato, "um indivíduo adquire um verdadeiro nome próprio ao cabo do mais severo exercício de despersonalização, quando se abre às multiplicidades que o atravessam de ponta a ponta, às intensidades que o percorrem". Metarmofoseados, uma professora e seus alunos, abrem-se às multiplicidades que os atravessam, e vivem, em um currículo, as mais simples e tocantes intensidades, experimentações e experiências: a alegria da expectativa de entrevistar um maestro; a emoção com a história de um maestro morrer com uma inflamação no pé provocada por uma batuta; a ansiedade de conhecer, ver, ouvir e sentir uma orquestra; o humor de conseguir imaginar ritmos e dançar com a imaginação; 
o prazer de aprender sobre diferentes instrumentos musicais; a potência provocada por músicas de diferentes tipos. Sem falar do formigamento produzido em todos quando se aventuram a aprender sobre as pinturas (desde aquelas dos azulejos de um banheiro, passando por pinturas de tecidos e roupas, até aquelas pinturas feitas pelos chamados "grandes pintores"). Nesses momentos, os habitantes do território curricular estão "despersonalizados" porque se tornam matilhas e povoam espaços escolares corriqueiros à espreita de sensações desconhecidas. Naquele momento, em que falam por afectos, existem menos diferenças entre a professora e as crianças do que entre a professora e as outras professoras. As ligações e conecções feitas entre professora e crianças fazem a rotina do currículo e o currículo-rotina dançarem.

\section{Exemplo 6: Afectos}

Uma variedade de aprendizagens não nomeadas pelos currículosdecalques e fazem sentir no currículo-diferença a necessidade de criação de um estilo, porque precisam invocar termos novos e novas linguagens para nomear e viver essas aprendizagens. O currículo diferença sente e faz sentir; produz sensações; faz as paixões murmurarem; e promove a guerra das alegrias contra as tristezas. Em um currículo, o Roberto aprende aos seis anos de idade a experimentar o devir-mestre em sua conexão com a professora.

Aprende a praticar a docência alegre, com humor, sem compromissos e sem enquadramentos. Admira-se e se encanta com a professora. Em alguns momentos, confunde-se e se faz confundir com a professora. Tal conexão o leva a ficar "desconsolado" quando sabe que sua professora vai viajar antes do período letivo terminar. Contagia com sua emoção a todos: sua professora, seus colegas, as pesquisadoras, as outras professoras participantes da pesquisa e sua família. A mãe também é contagiada pelo amor que une criança e professora tornando o currículo-por-eixos pequeno diante de tanta emoção, de tanta junção. É esse contágio que a faz escrever uma carta amorosa à professora do seu filho, que transcrevo:

Querida Ju, nunca, em momento algum, tive dúvidas em relação à sua competência, maturidade, responsabilidade e carinho em relação à escola, aos seus colegas e à meninada. No entanto, ontem, vi algo muito especial e marcante na minha vida [...]. Encontrei meu filho com uma carinha triste e angustiada, bem característica daqueles que sofrem por alguma coisa. E eu não estava errada, pois 
assim que chegamos em casa, ele começou a chorar convulsivamente e a dizer: "a Ju vai embora e eu só gosto dela e de mais ninguém, porque ela é a professora mais linda e a mais legal e eu não vou mais querer outra professora, só a Ju". Nesse momento, eu também chorei e entendi o quanto você representa para ele. E acredite, é muito mais do que nós próprios imaginávamos. Ele te ama. Essa é a palavra. É em nome desse sentimento que eu te escrevo para agradecer por tudo e desejar muita sorte na sua viagem e toda a felicidade possível no mundo. Além disso, quero que receba nosso presentinho, este desenho que ele passou um tempo bem grande fazendo, e o meu. Até breve, [...] pois assim como o Robertinho, sou uma chorona incontrolável e detesto despedidas. Vá com Deus, Feliz Natal! Te adoro!

Então, não é mesmo pura sensações o currículo-diferença? Em um currículo assim, já não há prescrições (faça desse modo), identidades (sou assim), verdades (é isso), pedagogias corretas (deve-se ensinar assim), tranquilidades (aprende-se se fizermos isso ou aquilo). Há apenas planos de orientação e programas de vida, "sempre modificados à medida que se fazem, traídos à medida que se aprofundam, como riachos que desfilam ou canais que se distribuem para que corra um fluxo". Em um currículo assim "você fez de todo-o-mundo um devir".

\section{POR ÚLTIMO: PARA CONTINUAR O JOGO DA DIFERENÇA NO CURRÍCULO...}

Inspirados no pensamento da diferença, não se olha para os currículos e pergunta se são verdadeiros ou falsos; qual é o mais crítico e o menos crítico; qual é oficial e qual é alternativo; qual é o tradicional e qual é o construtivista; qual é o público, o privado e o particular. Importam as sensações: o mundo do sensível. Interessa dizer o que faz "gritar", se desterritorializam coisas, se produzem bons encontros (aqueles que aumentam a potência dos envolvidos no processo). Importa sentir se são "importantes", "interessantes" e "notáveis".

Seguindo esses critérios, então, um currículo apresentado como forma ou valor eterno é o menos interessante. Currículos que enquadram, que buscam incansavelmente a identidade, que "não engendram um personagem conceitual que valha a pena", são desinteressantes. Se não trazem novidades para quem os vive, são pouco importantes. Mais interessantes e importantes 
são aqueles que desterritorializam, contagiam e provocam sensações: são os notáveis. Ser notável não é ser "correto", "simpático", "agradável”. Mesmo antipático, repulsivo, um currículo pode ser notável, ter estilo, compor, fazer fugir, deixar a diferença fazer os seus jogos.

Para deixar a diferença continuar o seu trabalho é preciso: possibilitar o acontecimento em um currículo! Deixar vazar! Fazer matilhas! Contagiar! Possibilitar um outro currículo; um currículo que pense com a diferença para ver, sentir e viver a vida em sua proliferação. Experimentar em um currículo: fazer currículo sem medo e sem programa. Arriscar! Com certas precauções, é claro, pois não podemos esquecer que a vida de muitos/as depende do currículo! Aventurar-se: aventurar junto com outras pessoas. Partilhar: coisas, afectos, sensações, desejos, aprendizagens...

Ao juntar-nos a outros/as em um currículo, pensar um novo estilo para um currículo. Fazer passar nesse território alguma energia. Deixar escapar, vazar sensações: uma corrente de energia. Fazer cortes provisórios na multiplicidade existente somente para espalhar, potencializar e seguir outras direções. Mostrar nossos pensamentos e paixões concretas que, em um currículo, arrancam-nos de nossa paralisia e dos poderes que fazem complô para que não pensemos nada. Partilhar! Compartilhar! Viajar sem mapas prévios! Fazer outros traçados! Fugir! Fazer composições e conexões! Inventar a cada vez suas orientações. Aprender! Gerar possibilidades de aprendizagem em contextos insuspeitados. Aumentar a potência de agir. Metamorfosear! Movimentar o próprio pensamento. Escapar das tentativas de captura. Deslizar. Fugir e criar um outro currículo que é e será único, inapreensível, incomunicável.

Isso tudo porque a diferença deleuziana é uma diferença sem outro; é a diferença em si. É o movimento que no meio da repetição se cria. A diferença se desenrola como movimento criador. Ela é devir; é movimento sem lei. Atua na zona do indeterminado e da interrogação. É experimental e multiplicável e replicável e repetível e dinâmica e criadora...

\section{REFERÊNCIAS BIBLIOGRÁFICAS}

BARREIROS, D. R.; FRANGELLA, R. C. O Currículo multieducação numa leitura pós-colonial: a identidade, o corpo e a sexualidade como entre-lugar no portal multiRio. In: REUNIÃO ANUAL DA ANPED, 27, 2004, Caxambu. Anais... Caxambu: Anped, 2004. (CD-ROM) 
CANEN, A. Educação multicultural, identidade nacional e pluralidade cultural: tensões e implicações curriculares. In: REUNIÃO ANUAL DA ANPED, 2 I , 1998, Caxambu. Programa e resumos... Caxambu: Anped, 1998. p. II4.

CORAZZA, S. Currículos alternativos-oficiais: o(s) risco(s) do hibridismo. In: CORAZZA, S. O Que quer um currículo? Petrópolis: Vozes, 200 I . p. 97- 127.

- Noologia do currículo: vagamundo, o problemático, e assentado, o resolvido. In: CORAZZA, S.; TADEU, T. Composições. Belo Horizonte: Autêntica, 2003. p. 19-34.

. Pesquisar o acontecimento: estudo em XII exemplos. In: TADEU, T.; CORAZZA, S.; ZORDAN, P. Linhas de escrita, Belo Horizonte: Autêntica, 2004. p. 7-78.

COSTA, T. A. A Noção de competência enquanto princípio de organização curricular. In: REUNIÃO ANUAL DA ANPED, 27, 2004. Anais... Caxambu: Anped, 2004. (CD-ROM)

DELEUZE, G. O Atual e o virtual. In: DELEUZE, G.; PARNET, C. Diálogos. São Paulo: Escuta, 1998. p. $173-179$.

. Conversações. Rio de Janeiro: Ed.34, 1992.

. Da superioridade da literatura anglo-americana. In: DELEUZE, G.; PARNET, C. Diálogos. São Paulo: Escuta, 1998. p.49-92.

. Désir et plaisir. Magazine Littéraire, Paris, n. 325, p.57-65, oct. 1994.

. Diferença e repetição. Rio de Janeiro: Graal, 1988.

. Foucault. São Paulo: Brasiliense, 1998a.

. El Intelectual y la política (entrevista com Gilles Deleuze). Barcelona: Archipiélago, n. 53, p. 68-69, 2002.

. Pensamento nômade. In: MARTON, S. (Org.). Nietzsche hoje? São Paulo: Brasiliense, 1985. p. 56-76.

. Políticas. In: DELEUZE, G.; PARNET, C. Diálogos. São Paulo: Escuta, 1998. p. $145-172$.

DELEUZE, G.; GUATTARI, F. Kafka: por uma literatura menor. Rio de Janeiro: Imago, 1977. . Mil platôs: capitalismo e esquisofrenia, v. I. Rio de Janeiro: Ed. 34, 1995 . Mil platôs: capitalismo e esquisofrenia, v.4. Rio de Janeiro: Ed. 34, 1997. . O Que é a filosofia? Rio de Janeiro: Ed. 34, 1997 a. 
FRAGA, A. Bom mocismo: configuração de um modo de ser adolescente. In: REUNIÃO ANUAL DA ANPED, 21, 1998, Caxambu. Programa e resumos.... Caxambu: Anped. p. 135.

GALO, S. Em torno de uma educação menor. Educação e Realidade, Porto Alegre, v.27, n.2, p.169-178, 2002.

GAUTHIER, C. Esquizoanálise do currículo. Educação e Realidade, Porto Alegre, v.27, n.2, p. I 43- 156, 2002.

HALL, S. Identidades culturais na pós-modernidade. Rio de Janeiro: DP\&A, 1997.

Quem precisa de identidade? In: SILVA, T. T. (Org.). Identidade e diferença. Petrópolis: Vozes, 2000. p. I03-133.

JÓDAR, F; GOMES, L. A. Devir-criança: experimentar e explorar outra educação. Educação e Realidade, Porto Alegre, v.27, n.2, p. 3 I-46, 2002.

LIMA, A. G. Currículos praticados: as identidades diatópicas na produção da cultura cotidiana das escolas. In: REUNIÃO ANUAL DA ANPED, 27, 2004, Caxambu. Anais... Caxambu: Anped, 2004. (CD-ROM)

PARAÍSO, M. Currículo e identidade: a produção de gênero, sexualidade e etnia na formação da professora. In: REUNIÃO ANUAL DAANPED, 21, 1998, Caxambu. Programa e resumos... Caxambu, Anped. p. 177.

. Currículo-mapa: o currículo pós-crítico. In: REUNIÃO ANUAL DAANPED, 26, 2003, Caxambu. Programa e resumos.... Caxambu: Anped. p. 204

. Pesquisas pós-críticas em educação no Brasil: esboço de um mapa. Cadernos de Pesquisa, São Paulo, v.34, n. 122, p.283-304, maio/ago. 2004.

SILVA, T. T. Currículo e identidades sociais: outros olhares. In: REUNIÃO ANUAL DAANPED, 18, 1995, Caxambu. Programa e resumos... Caxambu: Anped, 1995. p. I31.

. A Produção social da identidade e da diferença. In: SILVA, T. T. (Org.). Identidade e diferença. Petrópolis: Vozes, 2000. p.73-102.

TADEU T. A Arte do encontro e da composição: Spinoza + Currículo + Deleuze. In: CORAZZA, S.; TADEU, T. Composições. Belo Horizonte: Autêntica, 2003. p.59-74.

. Um plano de imanência para o currículo. In: TADEU, T.; CORAZZA, S.; ZORDAN, P. Linhas de escrita. Belo Horizonte: Autêntica, 2004. p. 127-205.

Recebido em: setembro de 2009

Aprovado para publicação em: março 2010 